\title{
Information Content Of Analyst Recommendations: Evidence From The Danish Biotechnology Sector
}

\author{
Omar Farooq, Ph.D., American University in Cairo, Egypt
}

\begin{abstract}
The purpose of this paper is to document the performance of analyst recommendations for biotechnology firms listed at the Copenhagen Stock Exchange during the period between 2001 and 2010. Our results show that analysts are able to reveal value relevant information via their recommendations. We report that buy recommendations are followed by significantly positive returns and sell recommendations are followed by significantly negative returns. However, we also show that performance of analyst recommendations is not uniform across all firms. It depends on the extent of information asymmetries present within firms. We show that analyst recommendations contain no value for firms with the least level of transparency (lowest intellectual capital disclosure, lowest analyst coverage, and lowest frequency of recommendations). However, as information environment improves, value of analyst recommendations also goes up. We recommend biotechnology firms to improve on their disclosure levels.
\end{abstract}

Keywords: Analyst Recommendations; Performance; Biotechnology; Intellectual Capital Disclosure; Analyst Coverage

\section{INTRODUCTION}

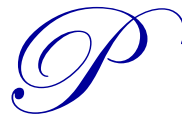

rior literature documents a strong link between analyst recommendations and subsequent stock returns. For instance, Womack (1996) documents that recommendation upgrades tend to outperform downgrades. In another related study, Jegadeesh and Kim (2006) find that stocks with the most favorable recommendations outperform stocks with the least favorable recommendations. This strand of literature argues that superior information processing skills, greater resources, and access to better quality information (both public and private) enable analysts to reveal value relevant information to investors via their recommendations (Stickel, 1995; Boni and Womack, 2003). However, their ability to disseminate valuable information for firms that are difficult to analyze is far from clear. Prior literature suggests that accuracy of analysts' research is an increasing function of transparency. Ashbaugh and Pincus (2001), for example, show that adoption of International Accounting Standards by firms positively affect accuracy of analysts' research. In another related study, Hope (2003) documents that analysts' accuracy improves with the improvement in firm-level public disclosures. Lang and Lundholm (1996) also report similar findings by showing that forecast accuracy is positively related to disclosure policies.

This paper is an attempt to document performance of analyst recommendations for biotechnology firms listed at the Copenhagen Stock Exchange during the period between 2001 and 2010. These firms are inherently hard to analyze. It is intuitive to believe that most of value of biotechnology firms is due to intellectual capital. Prior literature argues that firms with higher intellectual capital are, generally, hard to scrutinize. Holland and Johanson (2003), for instance, note that capital market agents do not value intellectual capital because they cannot comprehend it. Given the difficulty that is embedded in valuation of biotechnology firms, it is worth exploring the performance of analyst recommendations for these firms. Any evidence indicating that analysts are able to issue value relevant recommendations will be especially useful for investors, especially retail investors, who may shy away from investing in these firms due to their inability to comprehend complex information of these firms. Recommendations with higher value can induce these investors to trade in biotechnology firms. This will, in turn, provide much needed liquidity to these firms and will improve their value. 
Our results show that analysts are able to reveal value relevant information via their recommendations. We report that buy recommendations are followed by significantly positive returns and sell recommendations are followed by significantly negative returns. Our results are consistent with prior literature that considers analyst recommendations to be source of significant value for investors. How et al. (2007), for instance, conclude that aggregate changes in analyst recommendations are strong predictors of future performance. In another related study, He et al. (2013) come to same conclusion and document that stocks with favorable (unfavorable) recommendations on average outperform (underperformed) the benchmark index. However, we also show that performance of analyst recommendations is not uniform across all firms. It depends on the extent of information asymmetries present within firms. We show that analyst recommendations contain no value for firms with the least level of transparency (lowest intellectual capital disclosure, lowest analyst coverage, and lowest frequency of recommendations). However, as information environment improves, value of analyst recommendations also goes up. We report significant value of sell recommendations for firms with the highest level of transparency (highest intellectual capital disclosure, highest analyst coverage, and highest frequency of recommendations). For intermediate level of transparency, we report significant value of buy recommendations.

The remainder of the paper is structured as follows: Section 2 summarizes the data and Section 3 presents assessment of our hypothesis. Section 4 discusses our results and the paper concludes with Section 5.

\section{DATA}

This paper documents the value of analyst recommendations for the Danish biotechnology firms during the period between 2001 and 2010. We will, briefly, discuss the data in the following sub-sections.

\subsection{Analyst Recommendations}

We obtain the analyst recommendations data from the Institutional Brokers' Estimate System's (I/B/E/S) international history recommendation database. ${ }^{1}$ Table 1 documents the descriptive statistics for analyst recommendations during our sample period. Our results in Table 1 indicate that there are more buy recommendations than hold or sell recommendations throughout our sample. For instance, we show that more than $50 \%$ of recommendations were buy recommendations in 2001. Table 1 also report relatively fewer sell recommendations during most of the years in our sample period. For example, we report that analysts issued less than $20 \%$ of recommendations as sell recommendations in 2010. The results of Table 1 point towards wellestablished optimistic bias in analyst recommendations (Jegadeesh and Kim, 2006).

Table 1. Descriptive statistics for analyst recommendations

\begin{tabular}{c|c|c|c}
\hline Year & Buy & Sell & Hold \\
\hline 2001 & $66(56.90 \%)$ & $14(12.07 \%)$ & $36(31.03 \%)$ \\
\hline 2002 & $84(38.01 \%)$ & $68(30.77 \%)$ & $69(31.22 \%)$ \\
\hline 2003 & $70(37.63 \%)$ & $60(32.26 \%)$ & $56(30.11 \%)$ \\
\hline 2004 & $62(43.36 \%)$ & $44(30.77 \%)$ & $37(25.87 \%)$ \\
\hline 2005 & $70(43.21 \%)$ & $40(24.69 \%)$ & $52(32.10 \%)$ \\
\hline 2006 & $69(45.70 \%)$ & $47(31.13 \%)$ & $35(23.18 \%)$ \\
\hline 2007 & $70(35.71 \%)$ & $53(27.04 \%)$ & $73(37.24 \%)$ \\
\hline 2008 & $85(45.45 \%)$ & $45(24.06 \%)$ & $57(30.48 \%)$ \\
\hline 2009 & $80(35.87 \%)$ & $61(27.35 \%)$ & $82(36.77 \%)$ \\
\hline 2010 & $77(42.54 \%)$ & $34(18.78 \%)$ & $70(38.67 \%)$ \\
\hline
\end{tabular}

\subsection{Performance/Value of Analyst Recommendations}

This paper measures the performance of analyst recommendations with 1-Day post-recommendation return. We define 1-Day post-recommendation return (RET) as the difference between 1-Day post-recommendation gross

\footnotetext{
${ }^{1}$ For the purpose of this paper, we aggregate the I/B/E/S ratings of 1 and 2 as buy, and 4 and 5 as sell. Our decision to aggregate different ratings into a single category depends on the fact that there are very few strong sell recommendations (around $4 \%$ ) in our sample. Most of the unfavorable recommendations are sell.
} 
return and 1-Day post-recommendation market return. The stock price data and the corresponding market index data required to compute RET are obtained from the Datastream.

\subsection{Control Variables}

This paper uses the following firm-specific characteristics as control variables. The data for control variables is obtained from the Worldscope.

- SIZE: We measure size by log of market capitalization. Conventional wisdom suggests that large firms have lower agency problems due to increased interest from stock market participants (investors and analysts). Lower agency problems should lead to better stock price performance of large firms (Crawford et al., 2012).

- LEVERAGE: We measure leverage by total debt to total asset ratio. High leverage exposes firms to greater financial risk. High risk should result in lower stock returns (Mitton, 2002).

- GROWTH: This paper measures GROWTH by growth in earnings per share. Stock market participants are expected to favor high growth firms. Greater attention awarded to high growth firms should translate into better information environment. We argue that better information environment should be positively associated with stock returns. Jegadeesh and Livnat (2006) also document that firms with higher growth have better stock price performance.

- MBR: We define MBR as market value to book value ratio. Investors consider market value to book value ratio as a measure of risk. High risk deters investors and therefore deteriorates the information environment. As a result, we should expect negative relationship between market value to book value ratio and stock price performance.

Table 2, Panel A, documents the average/mean values for our control variables, while Table 2, Panel B, documents the correlation between different control variables. An interesting observation from Panel A is the relatively low level of leverage in biotechnology firms. Our results show that, on average, biotechnology firms have debt to asset ratio of less than $20 \%$. It may indicate lower ability of biotechnology firms to raise external capital. Given lower tangibility of their assets, it is possible that lenders do not provide enough capital to them. Furthermore, our results in Panel B show low correlation between the control variables. Therefore, we are able to use all control variables together in our regression analyses.

Table 2. Descriptive statistics of control variables

Panel A. Summary statistics of control variables

\begin{tabular}{l|r|c}
\hline & Mean & Median \\
\hline SIZE & 16.6518 & 16.7377 \\
\hline LEVERAGE & 0.1797 & 0.1381 \\
\hline MBR & 8.6725 & 4.6100 \\
\hline GROWTH & 0.0878 & 0.0715 \\
\hline
\end{tabular}

Panel B. Correlation matrix

\begin{tabular}{l|c|c|c|c}
\hline & SIZE & LEVERAGE & MBR & GROWTH \\
\hline SIZE & 1.0000 & & & \\
\hline LEVERAGE & -0.1733 & 1.0000 & & \\
\hline MBR & 0.0717 & 0.6318 & 1.0000 & 1.0000 \\
\hline GROWTH & 0.0454 & 0.0402 & 0.0649 & \\
\hline
\end{tabular}

\section{METHODOLOGY}

The most obvious question, while analyzing recommendations, is whether or not recommendations predict future returns. That is, do analysts uncover valuable information while making their recommendations? If so, their recommendations should predict future stock returns (Womack, 1996; Farooq, 2013). However, if the information they are revealing is already known to the public or is not valuable, there should be no relationship between their recommendations and future returns. In order to document whether analysts reveal any valuable information in their recommendations, we estimate the following regression equations with 1-Day post-recommendation return (RET) as 
a dependent variable and two dummy variables representing whether the recommendation is a buy recommendation (BUY) or whether it is a sell recommendation (SELL) as independent variables. It is important to mention here that we will not have a problem of perfect multicollinearity due to the presence of hold recommendations in our sample. If analysts are informative, the coefficient estimate of BUY should be positive and significant, while the coefficient estimate of SELL should be negative and significant. In addition, we also add log of firm's total assets (SIZE), total debt to total asset ratio (LEVERAGE), growth in earnings per share (GROWTH), and market-to-book ratio of a firm on the day of recommendation (MBR) as control variables. ${ }^{2}$ Our regression equations take the following form:

$$
R E T=\alpha+\beta_{1}(B U Y)+\beta_{2}(S E L L)+\varepsilon
$$

and

$$
R E T=\alpha+\beta_{1}(B U Y)+\beta_{2}(S E L L)+\beta_{3}(S I Z E)+\beta_{4}(L E V E R A G E)+\beta_{5}(G R O W T H)+\beta_{6}(M B R)+\varepsilon
$$

The results for our analysis are reported in Table 3. Our results show that buy recommendations are followed by significant positive returns and sell recommendations are followed by significant negative returns. We report significant positive coefficient for BUY and significant negative coefficient for SELL. We argue that investors in biotechnology sector can trade profitably on analyst recommendations. The results of this table are important because firms in biotechnology sectors are characterized by increased information asymmetries. Our results indicate that investors can reduce some of information asymmetries associated with biotechnology firms by following analyst recommendations.

\begin{tabular}{|c|c|c|}
\hline & Equation (1) & Equation (2) \\
\hline BUY & $0.0030^{*}$ & $0.0036^{* *}$ \\
\hline SELL & $-0.0053 * *$ & $-0.0053 * *$ \\
\hline SIZE & & $0.0017 * *$ \\
\hline LEVERAGE & & $0.0151 *$ \\
\hline MBV & & $-0.0120 *$ \\
\hline GROWTH & & $-0.0058^{*}$ \\
\hline Year Dummies & Yes & Yes \\
\hline No. of Observations & 1393 & 1393 \\
\hline F-value & 1.64 & 1.56 \\
\hline Adjusted R-square & 0.020 & 0.030 \\
\hline
\end{tabular}

Table 3. Performance of analyst recommendations

\section{DISCUSSION OF RESULTS}

\subsection{Intellectual Capital Disclosure and Performance of Analyst Recommendations}

Intellectual capital is one of the most important assets of any firm operating in the biotechnology sector. It can be considered as an information construct that embeds information about long-run sustainability (Hayton, 2005). Given that long-run sustainability is an important determinant of investors' decision to invest, lower disclosure regarding intellectual capital should increase information asymmetries. We argue that higher information asymmetries should reduce value of analyst recommendations. In order to test this conjecture, we divide our sample into three groups, ranging from high intellectual capital disclosure to low intellectual capital disclosure, and re-estimate Equation (2) for all groups. The data for intellectual capital disclosure is same as the one used in Farooq and Nielsen (2014). The results of our analysis are reported in Table 4. As expected, we should that analyst recommendations do not have any value for a group of firms that have the lowest disclosure of intellectual capital. However, for the other two groups, we show significant but asymmetric value of analyst recommendations. Our results show that sell recommendations have significant value for firms that have the highest disclosure of intellectual capital. For this

\footnotetext{
${ }^{2}$ We used robust regression in STATA for all of the regression estimations done in this paper. Robust regression produces those coefficients that are consistent with OLS assumptions.
} 
group, buy recommendations contain no value. We report significantly negative coefficient of SELL and insignificant coefficient of BUY for this group. We also show that sell recommendations have insignificant value for firms that have intermediate level of intellectual capital disclosure. We report insignificantly coefficient of SELL. For this group, buy recommendations contain significant value. We report significantly positive coefficient of BUY for this group.

Table 4. Effect of intellectual capital disclosure on the performance of analyst recommendations

\begin{tabular}{|c|c|c|c|}
\hline & High Disclosure & Medium Disclosure & Low Disclosure \\
\hline BUY & 0.0006 & $0.0070^{* * *}$ & 0.0023 \\
\hline SELL & $-0.0067 * * *$ & 0.0002 & -0.0096 \\
\hline SIZE & -0.0008 & $0.0019^{*}$ & 0.0031 \\
\hline LEVERAGE & -0.0297 & $0.0258^{*}$ & 0.0175 \\
\hline MBV & $0.4934 * * *$ & 0.0086 & $-0.0184 *$ \\
\hline GROWTH & $-0.0618^{* * *}$ & -0.0048 & -0.0043 \\
\hline Year Dummies & Yes & Yes & Yes \\
\hline No. of Observations & 410 & 455 & 528 \\
\hline F-value & 1.58 & 1.62 & 1.25 \\
\hline Adjusted R-square & 0.049 & 0.053 & 0.055 \\
\hline
\end{tabular}

\subsection{Analyst Coverage and Performance of Analyst Recommendations}

Analysts are the agents that collect, interpret, and disseminate public and private information (Michaely and Womack, 1999). In doing so, they reduce information asymmetries between firms and stock market participants. Farooq and Satt (2014) suggest that resolution of information asymmetries are more pronounced for those firms that have higher analyst coverage. Greater is the extent of analyst coverage, more is the information collected and disseminated. Consequently, we argue that performance of analyst recommendations should be an increasing function of the extent of analyst coverage. In order to test this conjecture, we divide our sample into three groups, ranging from high analyst coverage to low analyst coverage, and re-estimate Equation (2) for all groups. The results of our analysis are reported in Table 5. Our results are qualitatively the same as Table 4 in a way that we report no value of analyst recommendations for firms with the lowest analyst coverage. While for firms with the highest analyst coverage, we report significant value of sell recommendations and insignificant value of buy recommendations. For intermediate level of analyst coverage, we report insignificant value of sell recommendations and significant value of buy recommendations.

Table 5. Effect of analyst coverage on the performance of analyst recommendations

\begin{tabular}{|c|c|c|c|}
\hline & High Coverage & Medium Coverage & Low Coverage \\
\hline BUY & 0.0013 & $0.0056^{* *}$ & 0.0031 \\
\hline SELL & $-0.0063 * *$ & -0.0007 & -0.0105 \\
\hline SIZE & -0.0052 & $0.0037^{*}$ & $-0.0031^{*}$ \\
\hline LEVERAGE & -0.0246 & $0.0199 *$ & -0.0036 \\
\hline MBV & -0.0184 & -0.0085 & -0.0013 \\
\hline GROWTH & -0.0244 & -0.0087 & -0.0032 \\
\hline Year Dummies & Yes & Yes & Yes \\
\hline No. of Observations & 421 & 491 & 480 \\
\hline F-value & 2.10 & 1.39 & 1.79 \\
\hline Adjusted R-square & 0.073 & 0.043 & 0.074 \\
\hline
\end{tabular}

Note: The coefficients with $1 \%$ significance are followed by ***, coefficient with $5 \%$ by $* *$, and coefficients with $10 \%$ by *.

\subsection{Frequency of Recommendations and Performance of Analyst Recommendations}

Frequency of analyst recommendations is another measure that may proxy for the information environment of firm. We argue that greater is the frequency of analyst recommendations, more id the disclosure of relevant and timelier information. Given that analysts care about their reputation, they would issue recommendations more frequently for firms for which they have access to relevant information (Stickel, 1992). We argue that performance of analyst recommendation is higher for firms that have higher frequency of analyst recommendations. In order to test this 
conjecture, we divide our sample into three groups, ranging from high frequency to low frequency, and re-estimate Equation (2) for all groups. As was shown earlier, Table 6 shows qualitatively the same as before. We report no value of analyst recommendations for firms with the lowest frequency of recommendations. While for firms with the highest frequency of recommendations, we report significant value of sell recommendations and insignificant value of buy recommendations. For intermediate frequency of recommendations, we report insignificant value of sell recommendations and significant value of buy recommendations.

Table 6. Effect of frequency of recommendations on the performance of analyst recommendations

\begin{tabular}{|c|c|c|c|}
\hline & High Frequency & Medium Frequency & Low Frequency \\
\hline BUY & 0.0022 & $0.0063 * *$ & 0.0027 \\
\hline SELL & $-0.0065 * *$ & -0.0033 & -0.0062 \\
\hline SIZE & -0.0046 & 0.0015 & 0.0001 \\
\hline LEVERAGE & -0.0061 & $0.0465 * *$ & 0.0133 \\
\hline MBV & -0.2529 & -0.0227 & $-0.0186^{*}$ \\
\hline GROWTH & $0.0698 * *$ & -0.0099 & -0.0043 \\
\hline Year Dummies & Yes & Yes & Yes \\
\hline No. of Observations & 401 & 465 & 527 \\
\hline F-value & 2.29 & 1.95 & 1.36 \\
\hline Adjusted R-square & 0.080 & 0.050 & 0.054 \\
\hline
\end{tabular}

Note: The coefficients with $1 \%$ significance are followed by ***, coefficient with $5 \%$ by $* *$, and coefficients with $10 \%$ by $*$.

\section{CONCLUSION}

This paper documents the relationship between intellectual capital disclosure and value of analyst recommendations for biotechnology firms listed on the Copenhagen Stock Exchange during the period between 2001 and 2010. We show that analyst recommendations have significant investment value. We report that stock prices react significantly to buy and sell recommendations. Our results show that buy recommendations are followed by significantly positive returns and sell recommendations are followed by significantly negative returns during our sample period. The findings are consistent with prior literature that considers analyst recommendations to be source of significant value for investors (How et al., 2007; He et al., 2013). However, we show that value of analyst recommendations is not uniform across all firms. We show that analyst recommendations contain no value for firms with the least level of transparency (lowest intellectual capital disclosure, lowest analyst coverage, and lowest frequency of recommendations). However, as information environment improves, value of analyst recommendations also goes up. We report significant value of sell recommendations for firms with the highest level of transparency (highest intellectual capital disclosure, highest analyst coverage, and highest frequency of recommendations). For intermediate level of transparency, we report significant value of buy recommendations. This paper has important implications for firms operating in more opaque sectors, such as biotechnology firms. Our results show that analyst recommendations are more valuable for those firms that have better information environment. We argue that valuable recommendations can result in attracting investors. Greater interest from investors should, eventually, translate into higher valuation of these firms. Therefore, we propose that firms operating in more opaque sectors should expend considerable resources on improving their disclosures and information environment. We would like to mention that some caution should be observed towards our results. We did study all biotechnology firms in Denmark, but the sample size is relatively small. Therefore, our results may lack generalization.

\section{AUTHOR BIOGRAPHY}

Omar Farooq, Ph.D., American University in Cairo, Cairo, Egypt. Correspondence Address: Department of Management, American University in Cairo, Cairo, Egypt. Telephone: +20 1023760037.

Email: omar.farooq.awan@gmail.com 


\section{REFERENCES}

Ashbaugh, H. and Pincus, M., (2001). Domestic Accounting Standards, International Accounting Standards, and the Predictability of Earnings. Journal of Accounting Research, 39(3), pp. 417-434.

Boni, L. and Womack, K. (2003). Analysts, Industries, and Price Momentum? Journal of Financial and Quantitative Analysis, 41(1), pp. 85-109.

Crawford, S. S., Roulstone, D. T., and So, E. C., (2012). Analyst Initiations of Coverage and Stock Return Synchronicity. The Accounting Review, 87(5), pp. 1527, -1553.

Farooq, O., (2013). Who was Informative? Performance of Foreign and Local Analysts' Stock Recommendations during the Asian Financial Crisis. Research in International Business and Finance, 29, pp. 61-76.

Farooq, O. and Nielsen, C., (2014). Improving the Information Environment for Analysts: Which Intellectual Capital Disclosure Matters the Most? Journal of Intellectual Capital, 15(1), pp. 142-156.

Farooq, O. and Satt, H., (2014). Does Analyst Following Improve Firm Performance? Evidence from the MENA Region. Corporate Ownership and Control, 11(2), pp. 145-154.

Hayton, J. C., (2005). Competing in the New Economy: The Effect of Intellectual Capital on Corporate Entrepreneurship in High-technology New Ventures. R\&D Management, 35(2), pp. 137-155.

He, P. W., Grant, A., and Fabre, J., (2013). Economic Value of Analyst Recommendations in Australia: An Application of the Black-Litterman Asset Allocation Model. Accounting and Finance, 53(2), pp. 441-470.

Holland, J. and Johanson, U., (2003). Value-relevant Information on Corporate Intangibles - Creation, Use, and Barriers in Capital Markets - "between a rock and a hard place". Journal of Intellectual Capital, 4(4), pp. 465-486.

Hope, O-K., (2003). Disclosure Practices, Enforcement of Accounting Standards, and Analysts' Forecast Accuracy: An International Study. Journal of Accounting Research, 41(2), pp. 235-272.

Howe J. S., Unlu, E., and Yan, X., (2009). The Predictive Content of Aggregate Analyst Recommendations. Journal of Accounting Research, 47(3), pp. 799-821.

Jegadeesh, N. and Kim, W., (2006). Value of Analyst Recommendations: International Evidence. Journal of Financial Markets, 9(3), pp. 274-309.

Jegadeesh, N. and Livnat, J., (2006). Revenue Surprises and Stock Returns. Journal of Accounting and Economics, 41(1-2), pp. 147-171.

Lang, M. H. and Lundholm, R. J., (1996). Corporate Disclosure Policy and Analyst Behavior. The Accounting Review, 71(4), pp. 467-496.

Michaely, R. and Womack, K., (1999). Conflict of Interest and the Credibility of Underwriter Analyst Recommendations. Review of Financial Studies, 12(4), pp. 653-686.

Mitton, T., (2002). A Cross-firm Analysis of the Impact of Corporate Governance on the East Asian Financial Crisis. Journal of Financial Economics, 64(2), pp. 215-244.

Stickel, S. E., (1992). Reputation and Performance Among Security Analysts. Journal of Finance, 47(5), pp. $1811-1836$.

Stickel, S. E., (1995). The Anatomy of the Performance of Buy and Sell Recommendations. Financial Analysts Journal, 5(5)1, pp. 25-39.

Womack. K. L., (1996). Do Brokerage Analysts' Recommendations have Investment Value? Journal of Finance, 51(1), pp. 137167. 


\section{NOTES}

